\title{
Contribution of mono- and biarticular muscles to extending knee joint moments in runners and cyclists
}

Citation for published version (APA):

Savelberg, H. H. C. M., \& Meijer, K. (2003). Contribution of mono- and biarticular muscles to extending knee joint moments in runners and cyclists. Journal of Applied Physiology, 94(6), 2241-2248.

https://doi.org/10.1152/japplphysiol.01001.2002

Document status and date:

Published: 01/01/2003

DOI:

10.1152/japplphysiol.01001.2002

Document Version:

Publisher's PDF, also known as Version of record

Document license:

Taverne

Please check the document version of this publication:

- A submitted manuscript is the version of the article upon submission and before peer-review. There can be important differences between the submitted version and the official published version of record.

People interested in the research are advised to contact the author for the final version of the publication, or visit the DOI to the publisher's website.

- The final author version and the galley proof are versions of the publication after peer review.

- The final published version features the final layout of the paper including the volume, issue and page numbers.

Link to publication

\footnotetext{
General rights rights.

- You may freely distribute the URL identifying the publication in the public portal. please follow below link for the End User Agreement:

www.umlib.nl/taverne-license

Take down policy

If you believe that this document breaches copyright please contact us at:

repository@maastrichtuniversity.nl

providing details and we will investigate your claim.
}

Copyright and moral rights for the publications made accessible in the public portal are retained by the authors and/or other copyright owners and it is a condition of accessing publications that users recognise and abide by the legal requirements associated with these

- Users may download and print one copy of any publication from the public portal for the purpose of private study or research.

- You may not further distribute the material or use it for any profit-making activity or commercial gain

If the publication is distributed under the terms of Article $25 \mathrm{fa}$ of the Dutch Copyright Act, indicated by the "Taverne" license above, 


\title{
Contribution of mono- and biarticular muscles to extending knee joint moments in runners and cyclists
}

\author{
H. H. C. M. Savelberg' ${ }^{1}$ and K. Meijer ${ }^{1,2}$ \\ ${ }^{1}$ Department of Human Movement Science, Nutrition and Toxicology Research Institute Maastricht, \\ Faculty of Health Sciences, Universiteit Maastricht, NL-6200 MD Maastricht; and ${ }^{2}$ Faculty of \\ Biomedical Engineering, Technische Universiteit Eindhoven, 5600 MB Eindhoven, The Netherlands
}

Submitted 29 October 2002; accepted in final form 17 January 2003

\begin{abstract}
Savelberg, H. H. C. M., and K. Meijer. Contribution of mono- and biarticular muscles to extending knee joint moments in runners and cyclists. $J$ Appl Physiol 94: 2241-2248, 2003. First published January 17, 2003; 10.1152/ japplphysiol.01001.2002.-Motor actions are governed by coordinated activation of mono- and biarticular muscles. This study considered differences in mono- and biarticular knee extensors between runners and cyclists in the context of adaptations to task-specific movement requirements. Two hypotheses were tested: 1) the length-at-use hypothesis, which is that muscle adapts to have it operate around optimal length; and 2) the contraction-mode hypothesis, which is that eccentrically active muscles prefer to operate on the ascending limb of the length-force curve. Ten runners and ten cyclists performed maximal, isometric knee extensions on a dynamometer at five knee and four hip joint angles. This approach allowed the separation of the contribution of monoand biarticular extensors. Three major differences occurred: 1) compared with runners, monoarticular extensors of cyclists reach optimal length at larger muscle length; 2) in runners, optimal length of the biarticular extensor is shifted to larger lengths; and 3) the moment generated by monoarticular extensor was larger in cyclists. Mono- and biarticular extensors respond to different adaptation triggers in runners and cyclists. Monoarticular muscles seem to adapt to the length-at-use, whereas biarticular muscles were found to be sensitive to the contraction-mode hypothesis.
\end{abstract}

adaptation; optimal length; operating range; isometric contraction

SKELETAL MUSCLES HAVE A REMARKABLE ability to adapt to functional demands. Besides physiological and metabolic adaptations, structural adaptations in muscle size occur that have a profound effect on force production. In rehabilitation therapy and training, the adaptive properties of muscle are exploited to improve motor performance. The design of effective interventions to optimize movement performance requires knowledge regarding adaptation mechanisms of muscle, as well as an understanding of how muscles function during a motor task.

Running and cycling are motor tasks that impose different requirements on the knee extensor muscles.

Address for reprint requests and other correspondence: H. H. C. M. Savelberg, Dept. of Human Movement Science, Faculty of Health Science, Maastricht Univ., P.O. Box 616 , NL-6200 MD Maastricht, The Netherlands (E-mail: hans. savelberg@bw.unimaas.nl).
One could speculate that, in the muscles of persons who specialize in running or cycling, structural adaptations to those different requirements have occurred. Comparing properties of knee extensors in runners and cyclists could elucidate how structural muscle properties are related to task requirements. Van Ingen Schenau et al. $(21,22)$ have suggested that mono- and biarticular muscles have different roles in accomplishing joint angle changes and controlling joint moments. Consequently, it will be important to consider separately adaptations in either mono- or biarticular knee extensors.

Several differences between running and cycling can be derived from kinesiological studies. In cycling (19, 20 ), the knee joint is more flexed during the loaded phase than in running $(10,23)$ (Fig. 1). This indicates that, in cycling, the monoarticular vastus muscles work at longer lengths compared with running. Differences in length that differing knee joint angles would impose to the rectus femoris (RF) muscle are compensated by differences in hip joint angles between runners and cyclists. During running, the knee bends in the initial phase of stance. As a result, both the monoand the biarticular knee extensors perform an eccentric contraction during running. In cycling, such an eccentric phase is absent (Fig. 1). Furthermore, running requires a different contribution of mono- and biarticular muscles to an extending knee joint moment than cycling. Van Ingen Schenau et al. $(21,22)$ showed that, in an extending limb, the RF muscle is important for directing the external force forward. In cycling, this is the force on the pedal; in running, the force is applied to the ground. In running, a forward component of the external force is essential during the first one-half of the stance phase to control posture. In cycling at top dead center, a forward component of the force occurs $(18,22)$. This might be useful to enlarge the effective force component and optimize power output. As a consequence, the knee and hip joint angle patterns between running and cycling differ considerably at phases in which recruitment of $R F$ muscle is required (Fig. 1). It is likely that this affects the coordination between mono- and biarticular muscles.

The costs of publication of this article were defrayed in part by the payment of page charges. The article must therefore be hereby marked "advertisement" in accordance with 18 U.S.C. Section 1734 solely to indicate this fact. 


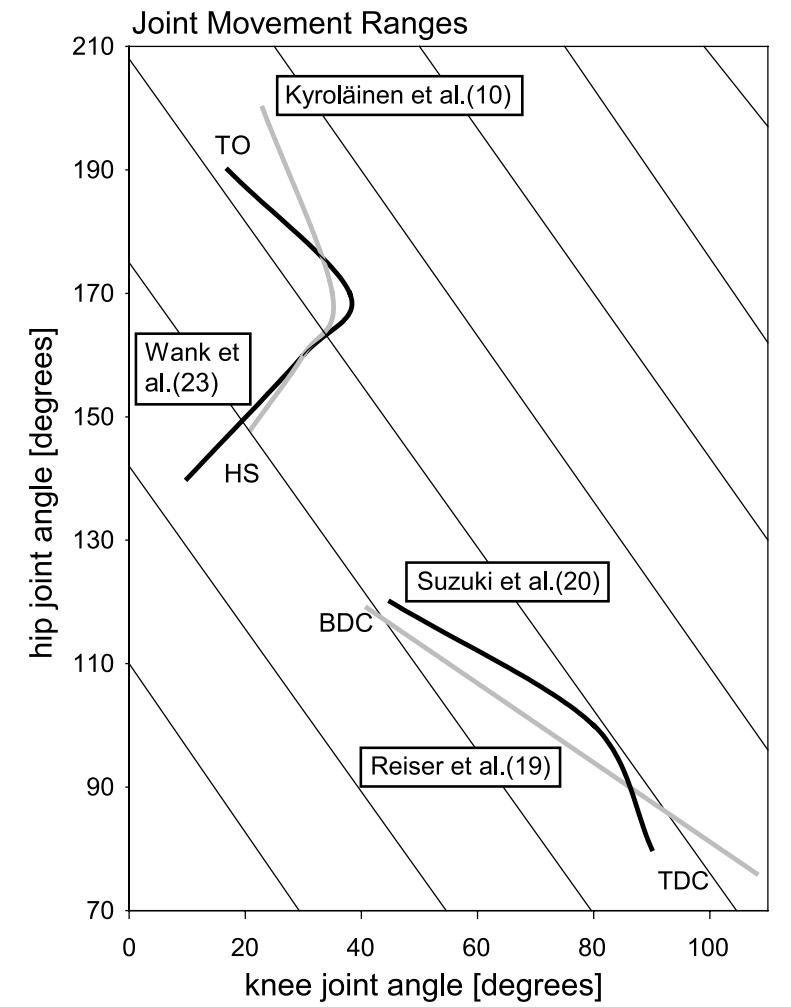

Fig. 1. Diagram showing hip (y-axis) and knee ( $x$-axis) joint angle changes for running $(10,23)$ and cycling $(19,20)$. The diagonal lines in this plot represent isolength curve for rectus femoris (RF) muscle (5); from bottom-left to top-right elongation of the muscle occurs. In running: HS, heel strike; TO, toe off. In cycling: TDC, top dead center; BDC, bottom dead center.

In animal experiments, it has been shown that a muscle adapts to the length with which it is most frequently confronted. It does so by adjusting the number of sarcomeres that are arranged in series $(2,8,13)$. The functional consequence of this adaptation is that the muscle can generate optimal force at longer muscle lengths. In addition, any change in the series arrangement of sarcomeres will affect the maximal contractile velocity and maximal power output of a muscle (11). It has also been suggested that eccentric contractions are a trigger for muscle to increase the number of sarcomeres in series. The rationale for this suggestion is that sarcomeres that operate on the descending limb of their length-force curve are prone to damage $(7,17)$. Thus adding sarcomeres in series would reduce the risk for damage by allowing more sarcomeres to operate on the ascending limb of their length-force curve.

It is difficult to determine a priori how muscles will adapt to running or cycling. Considering the task requirements for the knee extensors during cycling and running, in light of the aforementioned triggers for adaptation (muscle length and eccentric contractions), we can formulate the following hypotheses for the expected muscle adaptations. It is hypothesized that, if muscle length is the dominant trigger for adaptation (length-at-use hypothesis), then we would expect that, in cyclists, the monoarticular knee extensors would have adapted to generate maximal force at longer mus- cle lengths, that is, more flexed knee joint angles than in runners. Moreover, for the biarticular knee extensor, we would expect no differences in optimal length between runners and cyclists. Alternatively, it is hypothesized that, if eccentric contractions are the most important trigger for adaptation (contraction-mode hypothesis), both the monoarticular and biarticular knee extensors of runners will have adapted to generate maximal force at longer muscle lengths, that is, more flexed knee joint angles than in cyclists. To test these hypotheses, we have measured the knee extension moment-joint angle relationships for experienced runners and cyclists and extracted the contributions of the mono- and biarticular muscles from these data.

\section{METHODS}

Subjects. Ten cyclists and ten runners participated in this study. Each group consisted of eight men and two women. After the procedure had been explained, all subjects gave written, informed consent to participate. The human ethical review committee of Maastricht University approved the study. To be included as a cyclist, subjects had to ride at least $100 \mathrm{~km} / \mathrm{wk}$. Runners were selected from people who ran $>20$ $\mathrm{km} / \mathrm{wk}$. In this study, it has been assumed that training triggers the musculoskeletal system to adaptation and that differences found in this study between runners and cyclists represent adaptation to the specific requirements that these movement tasks impose on muscles.

Experimental setup. After a warming up on a cycle ergometer, the participants were positioned on a dynamometer $(\mathrm{Cy}-$ bex II). Before the testing, the subjects were acquainted with the protocol and the test setup. Subjects were instructed to execute maximal voluntary isometric contraction with the right leg. They were taught to generate maximal extending knee moment as quickly as possible after a sign of the tester. During the contraction, the subjects were fixed to the chair of the dynamometer by Velcro strips over the pelvis and the thigh. The lateral epicondyle of the right femur was aligned with the axis of rotation of the dynamometer.

Protocol. During a test, the subjects performed 20 maximal voluntary isometric contractions. The contractions were carried out in combinations of four different hip joint angles and five knee joint angles. The hip joint angle was set at 80,115 , 145 , and $175^{\circ}$. A completely extended trunk with the legs and the trunk aligned was defined as $180^{\circ}$. The knee joint angle was varied among $0,20,50,80$, and $110^{\circ}$. The extended leg was defined as $0^{\circ}$; increasing angle values corresponded to increasing flexion at the knee joint. In random order, the different joint configurations were applied. Between subsequent maximal voluntary isometric contractions, the subjects were allowed $3 \mathrm{~min}$ of rest. Each contraction lasted $\sim 2 \mathrm{~s}$. Immediately after a contraction, the subject was positioned in the joint configuration for the next contraction. In this way, preconditioning, i.e., creep, of the elastic components of the muscle-tendon complex was standardized. During $1 \mathrm{~s}$ before a contraction, the passive knee joint moment was recorded. This passive moment results from the weight of the limb and of the arm of the dynamometer and from the tension of passive structures in the limb. The passive moment could have a positive (knee-extending) or negative (knee-flexing) value. Subsequently, the gross active knee joint moment and its development were assessed.

Data analysis. The net active knee joint moment was calculated by distracting the passive knee joint moment from the maximal gross active knee joint moment. This maximal 
gross active knee joint moment was defined as the average value of the highest joint moment that was sustained for at least $0.5 \mathrm{~s}$.

To separate the contribution of the monoarticular vasti muscles from the biarticular RF muscle, the following procedure, adapted from Herzog et al. (6), was applied. First, each four active knee joint moments registered at one knee joint angle, but at four different hip joint angles, were considered as a function of normalized RF muscle length. The normalized RF muscle length was obtained by applying a model by Hawkins and Hull (5). Four of such data points differ mutually with respect to the contribution of the $\mathrm{RF}$ muscle. With the use of stepwise polynomial regression, a maximal firstdegree polynomial function was fitted to each set of four data points. This first step resulted in five linear relations between active joint moment and normalized RF muscle length (Fig. 2A). The differences between these five relations are determined by the length change in the vasti muscles as a result of the manipulated knee joint angle. The next step comprised assessing the average differences between these linear relationships for subsequent knee joint angles. The average difference between curves for subsequent knee joint angles within the range of common normalized $\mathrm{RF}$ muscle lengths was determined. Subsequent average differences were subtracted from the registered active knee joint data. In this way, for each knee joint and hip joint combination, the change in the contribution of $\mathrm{RF}$ muscle with respect to the contribution at a knee joint angle of $0^{\circ}$ and a hip joint angle of $80^{\circ}$ was obtained. With the use of stepwise polynomial regression, a maximal second-degree polynomial was fitted to this set of data (Fig. 2B), resulting in the change in extending knee joint moment caused by the RF muscle as a function of its normalized length. The final step involved subtracting the fitted contribution of the RF muscle at each joint angle combination from the recorded active knee joint moments, to obtain the change in the contribution of the vasti muscles as a function of knee joint angle. A maximal third-degree polynomial was fitted to these data, again applying a stepwise

\section{A Total extending knee joint moment}

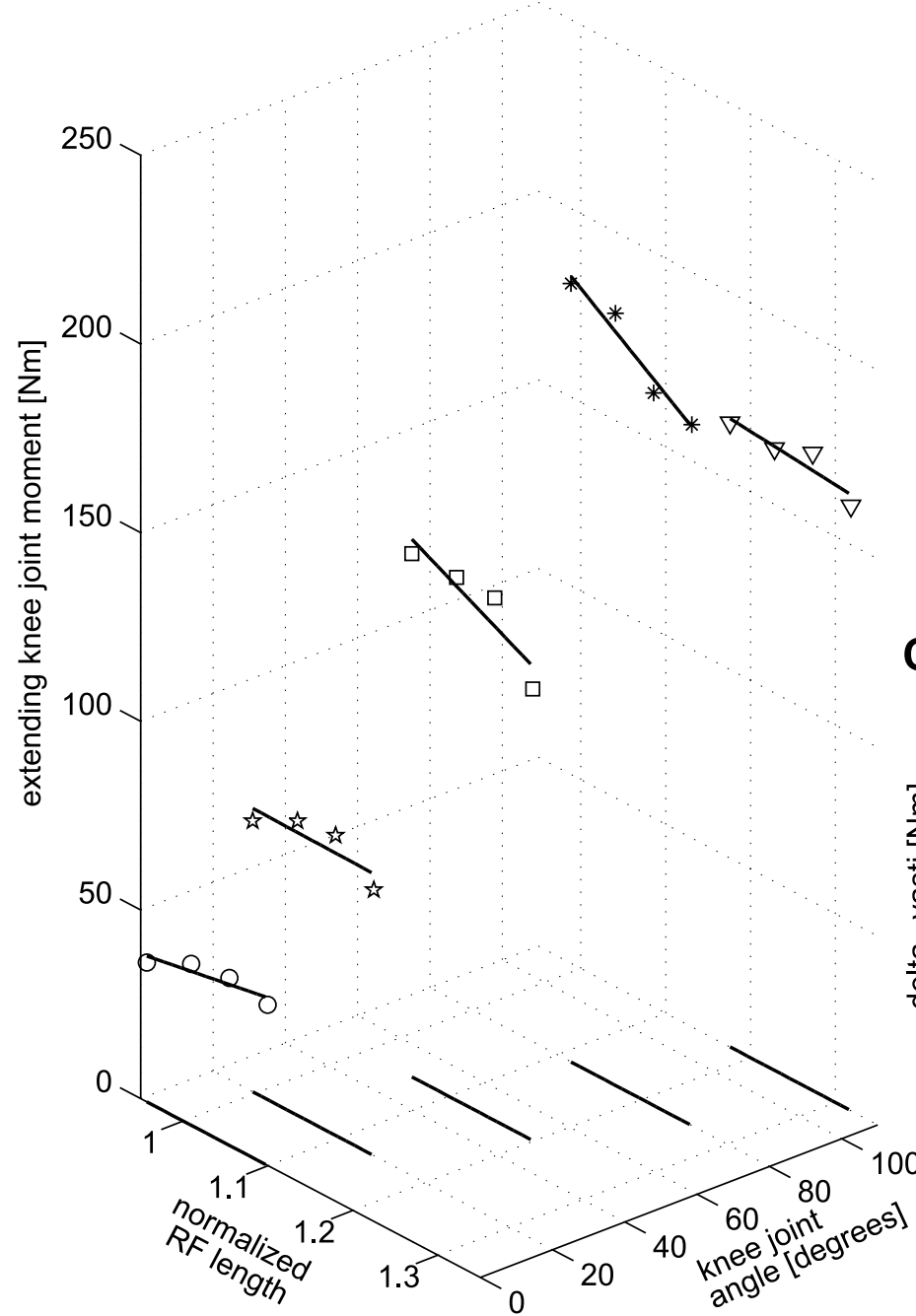

B 50 . Contribution of RF
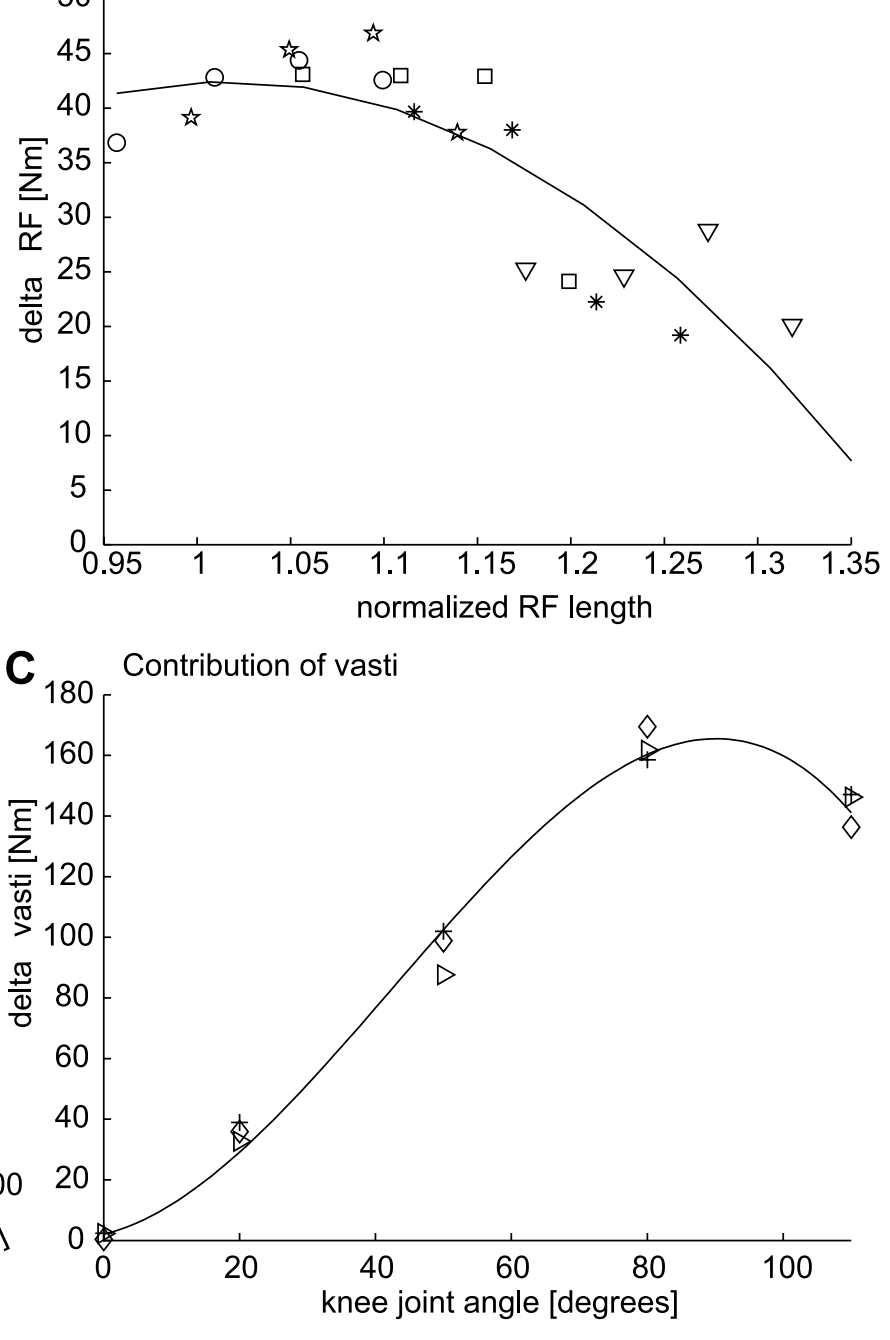

Fig. 2. Consecutive stages in the process of data analysis. A: total extending knee joint moment as a function of normalized length of RF muscle (5) and knee joint angle. Assessments at the same knee joint angle but at different hip joint angles are plotted in similar symbols. Regression lines are fitted through these subsets of data. $B$ : changed contribution of rectus femoris muscle $(\Delta \mathrm{RF})$ as a function of its normalized length. By stepwise polynomial regression, a curve was fitted to the data. $C$ : changed contribution of vasti muscles ( $\Delta$ vasti) as a function of knee joint angle. The fitted curve was obtained by stepwise polynomial regression. 
polynomial regression approach (Fig. $2 C$ ). A maximal firstdegree polynomial was fitted to the data obtain at one knee joint angle, because, among the four measurements involved, only the length of the RF muscle changed somewhat. This length change is not large enough to cause differences in force development that would necessitate a higher polynomial. For the data on the contribution of the RF muscle, a maximal second-degree polynomial was allowed, because the data could theoretically describe a considerable part of the range of the moment-length relationship. As the moment arm at the knee joint of the RF muscle is independent of the knee joint angle (16), the moment-length relationship will follow the force-length relationship, which needs at certain parts of its range at least a second-degree polynomial to be properly described. The moment-angle curve of the vasti muscles is determined by the moment-length curves of the individual vasti muscles and by the distribution of the optimal length of these three muscles over the knee joint angle. The latter variable allows the moment-angle curve of the concerted action of the vasti muscles to be wider than that of each of the individual vasti muscles. To allow the description of this additional complexity, a third-degree polynomial was permitted for this relationship.

It is important to notice that this approach did not enable assessment of absolute values for extending knee joint moments generated by the monoarticular muscle group or the biarticular muscle. Rather, the changed contribution of each muscle group with respect to the extending knee joint moment at a combination of reference joint angles was determined. These changed contributions will be referred to as the $\Delta$ vasti moment and the $\Delta \mathrm{RF}$ moment. The reference joint angle combination was $0^{\circ}$ at the knee joint and $80^{\circ}$ at the hip joint. Part of the total extending knee joint moment cannot be attributed to either the RF muscle or the vasti muscles. This nonattributable moment equals the sum of the minimal extending moment and the smallest value of $\triangle \mathrm{RF}$. If the slope of $\triangle R F$ is descending, the smallest value of $\Delta R F$ is negative, and, consequently, the nonattributable moment is smaller than the minimal extending moment.

Statistical analysis. For the $\Delta$ vasti and $\Delta R F$ curves, minimal and maximal values were determined. For the vasti muscles, the angle at which the contribution to the knee joint moment was maximal was assessed. For the total extending knee joint moment, minimal and maximal values were assessed as well as the hip and knee joint angles at which these values occurred. Differences for these variables between cyclists and runners were evaluated by using a Student $t$-test.

\section{RESULTS}

Groups differed with respect to body length $(P=$ $0.023)$ and body mass $(P=0.033)$; body mass index $(P=0.291)$, age $(P=0.192)$, and number of years participation in running or cycling $(P=0.575)$ were not different (cyclists: $1.84 \mathrm{~m}, 81.7 \mathrm{~kg}, 24.1 \mathrm{~m} / \mathrm{kg}^{2}, 34.0 \mathrm{yr}$, and $15.7 \mathrm{yr}$; runners: $1.77 \mathrm{~m}, 73.4 \mathrm{~kg}, 23.5 \mathrm{~m} / \mathrm{kg}^{2}, 38.8$ $\mathrm{yr}$, and $12.9 \mathrm{yr}$, respectively).

Maximal extending knee joint moment was not different between groups (cyclists $221.6 \mathrm{~N} \cdot \mathrm{m}$, runners $194.4 \mathrm{~N} \cdot \mathrm{m}, P=0.111$; Table 1 ). However, these maximal moments were generated at different knee joint angles for the groups $(P=0.043)$ : cyclists generated maximal extending moments at a knee joint angle of $79.6^{\circ}$, and runners accomplished this at $74.4^{\circ}$. The minimal knee joint moments were not different; however, the ratio between maximal and minimal knee joint moment varied over groups $(P=0.020)$, as did the absolute change between minimal and maximal moment ( $P=0.045$; Fig. 3 ). For runners, the minimal moment was $28.0 \%$ of the maximal moment; for cyclists, this ratio was only $21.9 \%$. The absolute change from minimal to maximal moment accounted for 140.5 $\mathrm{N} \cdot \mathrm{m}$ for runners and $173.2 \mathrm{~N} \cdot \mathrm{m}$ for cyclists. The nonattributable joint moment differed between the categories of athletes $(P=0.009)$. For runners, it accounted for $25.6 \%$ of the maximal moment; for cyclists it was only $15.4 \%$ (Fig. 3).

In the knee joint angle range considered, all vasti muscles operated throughout almost the entire range of the moment-angle diagram. Both the ascending and the descending limb are covered. The knee joint angle at which the vasti muscles generate a maximal moment differed between the groups $(P=0.032)$. Runners generated the maximal moment, with the monoarticular vasti muscles at $7^{\circ}$ more extended legs than cyclists (runners $73.9^{\circ}$, cyclists $80.8^{\circ}$ ). The magnitude of $\Delta$ vasti displayed a significant difference between both categories $(P=0.008)$ : for runners it accounted for 110.9 $\mathrm{N} \cdot \mathrm{m}$, and for cyclists it was on the average $154.3 \mathrm{~N} \cdot \mathrm{m}$. Also, when normalized to the maximally generated moment, this difference is presented $(P=0.019)$. For

Table 1. Major dependent variables for runners and cyclists

\begin{tabular}{|c|c|c|c|}
\hline Variable & Cyclists & Runners & $P$ Value \\
\hline Maximal extending joint moment, $\mathrm{N} \cdot \mathrm{m}$ & $221.6 \pm 49.3$ & $194.4 \pm 47.3$ & 0.111 \\
\hline Knee joint angle at maximal, ${ }^{\circ}$ & $79.6 \pm 7.0$ & $74.4 \pm 5.9$ & 0.043 \\
\hline Range of change of extending joint moment, $\mathrm{N} \cdot \mathrm{m}$ & $173.2 \pm 42.4$ & $140.5 \pm 39.3$ & 0.045 \\
\hline Nonattributable extending joint moment, $\%$ & $15.4 \pm 11.1$ & $25.6 \pm 5.3$ & 0.008 \\
\hline \multicolumn{4}{|l|}{ Moment contributed by vasti muscles } \\
\hline Knee joint angle at maximal vasti contribution, ${ }^{\circ}$ & $80.8 \pm 8.4$ & $73.9 \pm 7.2$ & 0.032 \\
\hline \multicolumn{4}{|l|}{ Moment contribute by RF muscle } \\
\hline Magnitude $\Delta \mathrm{RF}, \mathrm{N} \cdot \mathrm{m}$ & $39.8 \pm 18.2$ & $43.3 \pm 39.3$ & 0.400 \\
\hline Optimal normalized RF length, AU & $1.12 \pm 0.15$ & $1.19 \pm 0.11$ & 0.107 \\
\hline
\end{tabular}

Values are means \pm SD. $\Delta$ vasti, Changed contribution of vasti muscle group; $\Delta$ RF, changed contribution of rectus femoris (RF) muscle; AU, arbitrary units. 


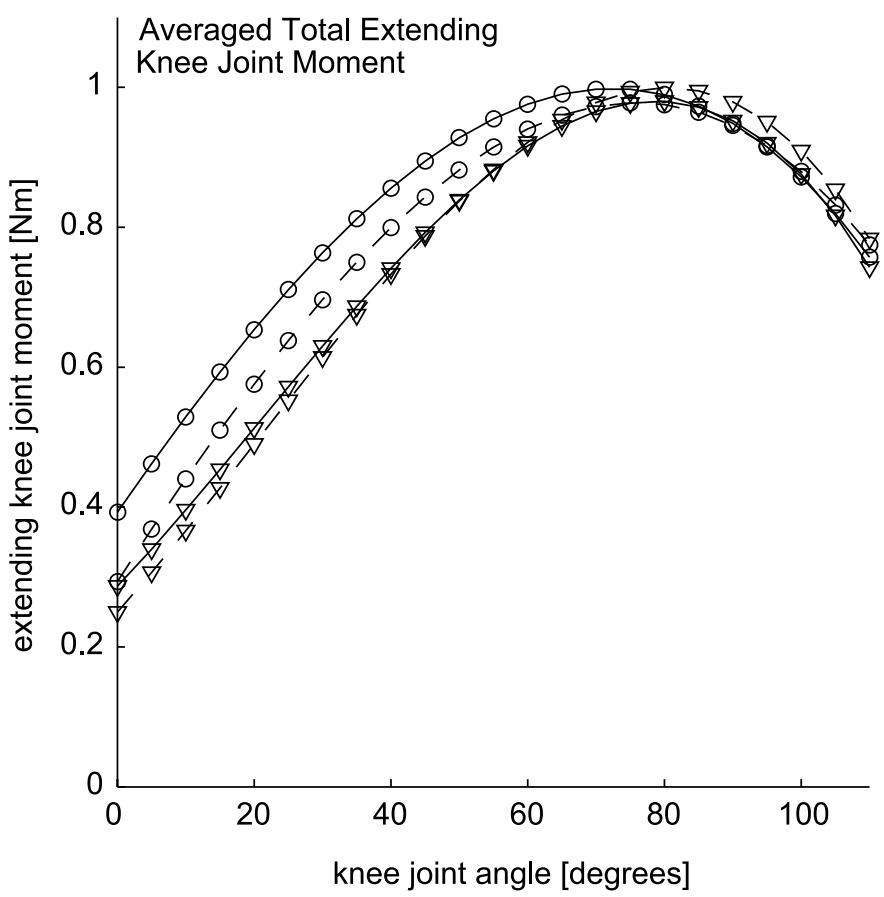

Fig. 3. Normalized, averaged total extending knee joint moments for runners $(\bigcirc)$ and cyclists $(\nabla)$ as a function of knee joint angle. Solid lines, data at the fully extended hip joint; dashed lines, data at maximally flexed hip joint angles. For each population, data were normalized to the maximal averaged joint moment of that group.

cyclists, the magnitude of $\Delta$ vasti was $70 \%$ of the maximal extending knee joint moment; for runners, it was only $57.7 \%$.

Contrary to the vasti muscles, the $\Delta \mathrm{RF}$ curves covered only a limited part of the moment-length diagram. The shape of the RF muscle curves differed widely among subjects. Within the range of knee and hip joint angles imposed, ascending, descending, and symmetric $\Delta \mathrm{RF}$ curves were found. On the basis of their optimal length, $\Delta \mathrm{RF}$ curves were ascribed to one of five classes. Eight of the ten $\Delta R F$ curves of the runners were classified in one of both classes at the upper end. These classes represented the ascending curves with the higher optimal lengths. The curves for the cyclists were evenly distributed over the five classes. The difference in this distribution between runners and cyclists was not statistically significant. The magnitude of $\triangle \mathrm{RF}$ did not differ between runners $(43.3 \mathrm{~N} \cdot \mathrm{m})$ and cyclists $(39.8 \mathrm{~N} \cdot \mathrm{m})$.

In an additional analysis, two different populations of the cyclists were compared: a population with ascending moment-length curves $(n=6)$ and another with descending moment-length curves ( $n=4$; Fig. 4). The descending group showed a clear shift of the optimal RF length for cyclists to shorter muscle lengths compared with runners $(P<0.0001)$ and with the ascending group $(P=0.0005$; Table 2$)$. The optimal RF length for the ascending group and the runners did not differ. This distinction in two groups of cyclists was also present in the $\Delta$ vasti curve (Fig. 5). The ascending $\mathrm{RF}$ cyclist population did not differ significantly from the runners with respect to optimal knee joint angle for the vasti muscles. However, the descending RF cyclists have a significantly larger optimal knee joint angle $\left(86.8^{\circ}\right)$ than the ascending $\mathrm{RF}$ cyclists $\left(76.8^{\circ} ; P=\right.$ $0.034)$ and the runners $(P=0.011)$. A similar pattern, significant difference between the descending $\mathrm{RF}$ cyclists and both of the other groups, but not between both of the other groups, is also present for the ratio of the magnitude of $\Delta$ vasti and the total knee-extending knee joint moment and for the ratio of the minimal and maximal extending knee joint moment. The magnitude of $\Delta$ vasti does not differ significantly between both subcategories of cyclists.

An inverse relation (correlation coefficient: -0.58) was found for the optimal length of RF and optimal knee joint angle of vasti muscles. In subjects with shorter optimal lengths for RF muscle, the vasti muscles have larger, more flexed optimal knee joint angles. The amount of the moment change that is generated by changes in the contribution of the vasti muscles correlated negatively to the optimal length of $\mathrm{RF}$ muscle (correlation coefficient: -0.67 ).

\section{DISCUSSION}

This study considered the hypothesis that, because of different movement and force requirements between runners and cyclists, the mono- and biarticular parts of the quadriceps muscles of these two populations would show adaptations either triggered by the length ranges at which they are most often used or triggered by the contraction mode, i.e., concentric or eccentric. Comparison of maximal knee-extending moments revealed no differences between cyclists and runners. However, dissecting the contribution of mono- and biarticular knee extensors revealed three major differences in moment length-angle curves between runners and cyclists: 1) the vasti muscles of cyclists attain their optimal joint angle at more flexed knee joint configurations, 2) the magnitude in $\Delta$ vasti was larger for cyclists compared with runners, and 3) the RF muscle of runners produces optimal moment at longer muscle lengths compared with that of cyclists.

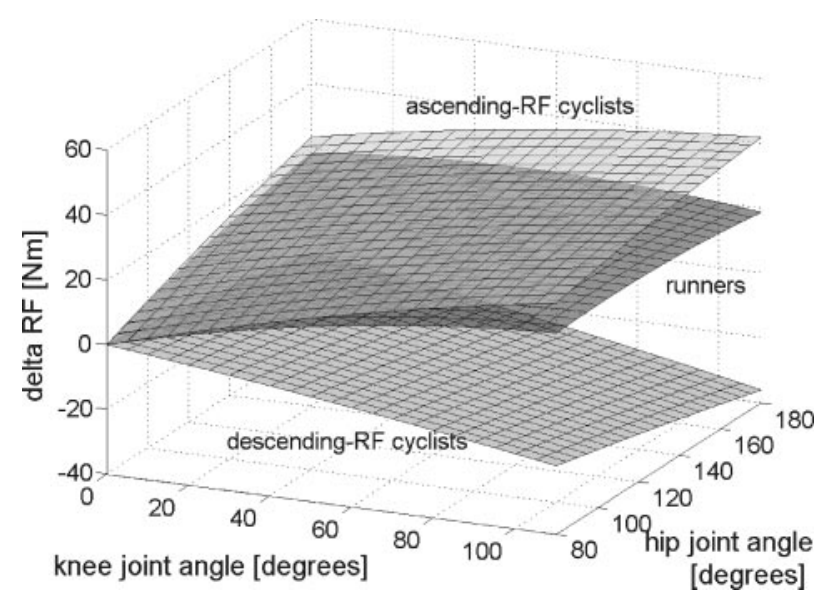

Fig. 4. The $\triangle \mathrm{RF}$ curve as a function of knee joint and hip joint angle for runners, ascending RF cyclists, and descending RF cyclists. The joint moment at the reference configuration (knee joint angle $0^{\circ}$ and hip joint angle $80^{\circ}$ ) is zero by definition. 
Table 2. Major dependent variables for cyclists with either a descending or an ascending moment-length curve for the rectus femoris muscle

\begin{tabular}{|c|c|c|c|}
\hline Variable & Cyclists, Descending RF & Cyclists, Ascending RF & $P$ Value \\
\hline Maximal extending joint moment, $\mathrm{N} \cdot \mathrm{m}$ & $193.4 \pm 51.3$ & $240.4 \pm 41.6$ & 0.091 \\
\hline Knee joint angle at maximal, ${ }^{\circ}$ & $81.8 \pm 10.2$ & $78 \pm 4.5$ & 0.273 \\
\hline Range of change of extending joint moment, $\mathrm{N} \cdot \mathrm{m}$ & $156.1 \pm 38.6$ & $184.6 \pm 44.2$ & 0.157 \\
\hline Nonattributable extending joint moment, $\%$ & $5.5 \pm 9.6$ & $22.1 \pm 5.9$ & 0.015 \\
\hline \multicolumn{4}{|l|}{ Moment contributed by vasti muscles } \\
\hline Knee joint angle at maximal vasti contribution, ${ }^{\circ}$ & $86.8 \pm 6.9$ & $76.8 \pm 7.2$ & 0.034 \\
\hline \multicolumn{4}{|l|}{ Moment contribute by RF muscle } \\
\hline Magnitude $\Delta \mathrm{RF}, \mathrm{N} \cdot \mathrm{m}$ & $36.3 \pm 17.2$ & $42.1 \pm 20.0$ & 0.318 \\
\hline Optimal normalized RF length, AU & $0.96 \pm 0.03$ & $1.22 \pm 0.10$ & 0.000 \\
\hline
\end{tabular}

Values are means \pm SD.

The data on vasti muscles support the length-at-use hypothesis. The finding that cyclists attain optimal vasti muscle moment at a larger joint angle compared with runners is compatible with the fact that cyclists use vasti muscles at more flexed knee-joint angles. The contraction-mode hypothesis cannot explain this result for vasti muscles. Interpretation of the data on $R F$ muscle was less straightforward. The data showed that two groups of cyclists could be distinguished: an ascending RF curve group and a descending RF curve group. Differences in properties of the vasti muscles were found to be associated with the RF-based distinction. In a study on four runners and three cyclists, Herzog et al. (6) reported ascending moment-length curves for RF muscle of runners and descending curves for cyclists. In contrast to the present study, the runners and cyclists tested by Herzog et al. were highly trained elite athletes. The subjects in our study practiced at a recreational level. Because of this difference in level of practice, more vigorous adaptations can be expected in the study by Herzog et al. (6). Therefore, we

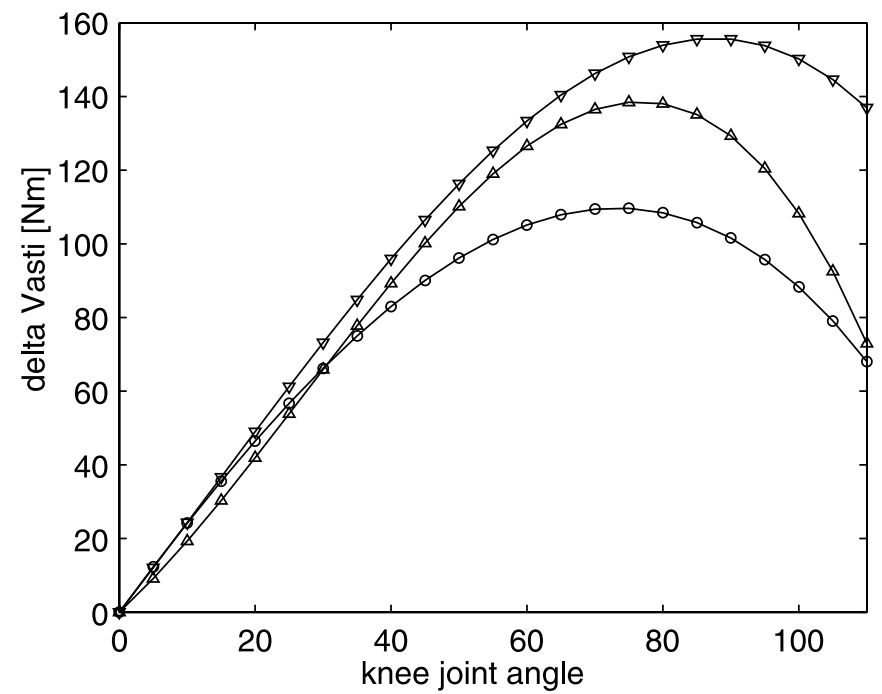

Fig. 5. The $\Delta$ vasti curve as a function of knee joint angle for runners $(\circ)$, ascending RF cyclists $(\triangle)$, and descending RF cyclists $(\nabla)$. The joint moment at a knee joint angle of $0^{\circ}$ is zero by definition. conclude that the two subgroups of cyclists in this study, ascending $R F$ and descending $R F$, represent different degrees of adaptation. It is assumed that the descending $\mathrm{RF}$ group represents a more highly trained population.

Comparison of the data of runners with the descending RF cyclists indicates that the length-at-use hypothesis cannot explain the adaptations found for the $R F$ muscle. According to this hypothesis, no differences in optimal length for this muscle were expected; however, the data show large differences between the runners and the descending RF cyclists. The significantly larger optimal length of RF muscle in runners, who use this muscle partly eccentrically, supports the contraction-mode hypothesis.

The different adaptations found in vasti muscles and $\mathrm{RF}$ muscle indicate that the proposed adaptation mechanisms do not exclude each other; in fact, they can be active simultaneously. Assuming that humans are born runners and that cycling is an acquired skill, we suggest that cyclists have adapted their muscle-tendon morphology. It looks like cyclists adapt vasti muscles to a longer length at use and that, in these athletes, $\mathrm{RF}$ muscle adjusts to smaller optimal length as the trigger to maintain optimal length at large muscle length is absent.

Several assumptions underlie this study and its design. The first assumption is that the measured joint moments are not confounded by cocontraction of the knee flexor muscles, or that at least the knee joint moment registered by the Cybex II is only, for a negligible part, affected by flexor muscles. Based on neurophysiological knowledge, it is assumed that, during a maximal voluntary contraction of the knee extensors, activation of the knee flexor muscles is prohibited by reciprocal inhibition (3). A second assumption is that, under isometric conditions, only the length of monoarticular muscles determines their mechanical output, and thus only changes in the knee joint angle affect it. Manipulation of the hip joint angle is assumed to have no effect on the length of vasti muscles. Recent studies (e.g., Ref. 14) have indicated that adjacent muscles can affect each other's force production through myofascial 
connections. However, in this study, the variation in $\Delta$ vasti was found to be independent from the hip joint angle (Fig. 2C). Because the force generated by the RF muscle does not affect that generated by the vasti muscles, it can be concluded that opposite interaction is also absent and that the mechanical output of the $\mathrm{RF}$ muscle is determined only by its own length. A final, important assumption is that subjects are able to perform voluntary knee extensions with maximal effort in each combination of knee and hip joint angle. After each contraction, subjects were asked whether they thought the attempt to be maximal. If the answer was negative, that specific trial was repeated. This occurred only a few times during the experiments. Given the large number of attempts at different joint angle combinations, one or a few incidental violations of this assumption would merely increase the variability of data around fitted curves and would only reduce the change of statistically significant differences. It is unlikely that such violations create differences between groups that do not really exist. As a measure for the ability of a subject to repeatedly contract maximally, the correlation between the measured knee joint moments and the fitted values was determined. It was found to vary between 0.941 and 0.997 over subjects. On the average, it did not appear to be different for runners and cyclists $(P=0.177)$.

The difference in magnitude of $\Delta$ vasti between runners and cyclists indicates a difference in physiological cross-sectional area (PCSA) of vasti muscles. The difference in optimal joint angle for this muscle can be the result of at least three different mechanisms. Optimal length of a muscle can be affected by the number of sarcomeres in series $(8,11,13)$, by the stiffness of the muscle-tendon complex (15), or, in the case of vasti muscles, if different heads of a muscle group have different optimal lengths, by increased maximal force of one of these heads.

The different optimal lengths of the vasti muscles would require some 15\% extra sarcomeres in series in descending RF cyclists compared with runners. This is in accordance with results from experimental studies on animals that reported variations in the number of sarcomeres of $20 \%$ maximal $(2,8,13)$. In the descending $\mathrm{RF}$ cyclists, the optimal length of RF muscle occurred at $80 \%$ of the optimal length in runners. This is similar to the difference reported by Herzog et al. (6). As in the RF muscle, the muscle fiber length is $25 \%$ of the muscle length $(16,24)$; a $20 \%$ shorter optimal muscle length for cyclists implies $80 \%$ less sarcomeres in series. This is beyond imagination. It can be concluded that other factors have to be involved to accomplish the different optimal lengths of RF muscle.

Increasing the stiffness of the series elastic component of a muscle results in a shift of optimal length to shorter muscle length. Running (9) and eccentric training (12) have been reported to increase muscle stiffness. Thus, if changes in stiffness underlie the differences found in our study, it would be expected that runners would have smaller optimal lengths than cy- clists. This is what is found in vasti muscles but not in RF muscle.

As a third alternative, a difference in the balance between the three heads of vasti muscles can explain the difference in optimal length of this muscle between runners and cyclists. If the three heads of the vasti muscles do not have their optimal length at the same knee joint angle, differences between runners and cyclists in the maximal forces generated by each of the three heads of this muscle will become apparent as a difference in the optimal length of the group. The present data do not allow statements on distribution of optimal length among the three heads of vasti muscles, nor on differences in PCSA among these heads. But it is worthwhile to note that Häkkinen et al. (4) found that, in older women, strength training affected crosssectional area of the four heads of the quadriceps femoris muscle differently.

In conclusion, in cyclists, a larger PCSA of vasti muscles is necessary to allow a larger magnitude of $\Delta$ vasti. This increment of PCSA of one of the heads of vasti muscles may contribute to the change in optimal length of this muscle group. Furthermore, a higher number of sarcomeres in series and a lower stiffness in cyclists than in runners can possibly contribute to the differences in optimal length between both groups of athletes. The difference in the optimal length of $\mathrm{RF}$ muscle is too large to be attributed completely to differences in numbers of sarcomeres in series. Also, this difference is in contrast to what would have been expected based on increased stiffness in runners. Becker and Awiszus (1) reported that voluntary activation of quadriceps depends on knee joint angle. A considerable difference between runners and cyclists in the dependence of activation on knee joint angle might theoretically contribute to the difference in optimal length of RF muscle and vasti muscles. However, the experimental data of this study cannot be used to resolve this issue.

It is tempting to speculate on the functional consequences of differences found in this study. Cycling and running impose very different requirements on the muscles of the lower limbs. The differences found have functional relevance. The higher peak moment and the larger optimum muscle length of the vasti muscles of the cyclist compared with the runners allow this muscle to generate more power (11) in cycling. Similarly, the reduced contribution of the RF muscle to the total moment in cyclists fits with the reduced need for this muscle to direct the external force during cycling (see the introduction). In runners, the longer optimum length of the $\mathrm{RF}$ muscle ensures that this muscles functions at the ascending limb of its length-force curve. This aids the stability of the knee joint during impact, as well as reduces the susceptibility for damage during eccentric contractions (17). Furthermore, the relatively large contribution of this muscle to the total knee extension moment gives runners a better potential to direct the external forces optimally $(21,22)$.

In summary, this study showed that both mono- and biarticular knee extensors have different moment 
length-angle curves in runners and cyclists. These differences between runners and cyclists do not become apparent when the total extending joint moment patterns are considered. It should thus be concluded that assessing total extending joint moment patterns and, even more, only assessing maximal extending moments are not sufficient to characterize properties of muscle groups. In addition, the results of this study challenge assumptions on fixed optimal lengths of muscles and fixed ratio between muscles, as are often used in simulation studies. This study confirms the results of Herzog et al. (6) with respect to biarticular knee extensors; moreover, it extends that study with respect to monoarticular knee extensors and with respect to the interpretation of data. Herzog et al. interpreted their data on RF muscle as a support for the lengthat-use hypothesis as a trigger for adaptation. In this study, we concluded that more triggers could be active. Moreover, it is suggested that the length at use triggers adaptation in the monoarticular vasti muscles, whereas the biarticular RF muscle appears rather to be sensible to contraction-mode triggers.

The authors thank Sigrid Braspenning for valuable contribution to data acquisition and processing.

\section{REFERENCES}

1. Becker R and Awiszus F. Physiological alterations of maximal voluntary quadriceps activation by changes of knee joint angle. Muscle Nerve 24: 667-672, 2001.

2. Burkholder TJ and Lieber RL. Sarcomere number adaptation after retinaculum transection in adult mice. J Exp Biol 201: 309-316, 1998.

3. Crone C. Reciprocal inhibition in man. Dan Med Bull 40: 571$581,1993$.

4. Häkkinen K, Pakarinen A, Kraemer WJ, Häkkinen A, Valkeinen H, and Markku A. Selective muscle hypertrophy, changes in EMG and force and serum hormones during strength training in older women. J Appl Physiol 91: 569-580, 2001.

5. Hawkins D and Hull ML. A method for determining lower extremity muscle-tendon lengths during flexion/extension movements. J Biomech 23: 487-494, 1990.

6. Herzog W, Guimaraes AC, Anton MG, and Carter-Erdman KA. Moment-length relations of rectus femoris of speed skaters/ cyclists and runners. Med Sci Sports Exerc 23: 1289-1296, 1991.

7. Hesselink MK, Kuipers H, Geurten P, and Van Straaten $H$. Structural muscle damage and muscle strength after incremental number of isometric and forced lengthening contractions. J Muscle Res Cell Motil 17: 335-341, 1996.
8. Koh TJ and Herzog W. Increasing the moment arm of the tibialis anterior induces structural and functional adaptation. Implications for tendon transfer. J Biomech 31: 593-599, 1998.

9. Kubo K, Kanehisa H, Kawakami Y, and Fukunaga T. Elastic properties of muscle-tendon complex in long-distance runners. Eur J Appl Physiol 81: 181-187, 2000.

10. Kyröläinen H, Pullinen T, Candau R, Avela J, Huttunen P, and Komi P. Effects of marathon running on running economy and kinematics. Eur J Appl Physiol 82: 297-304, 2000.

11. Lieber RL and Fridén J. Functional and clinical significance of skeletal muscle architecture. Muscle Nerve 23: 1647-1666, 2000 .

12. Lindstedt SL, Reich TE, Keim P, and LaStayo PC. Do muscles function as adaptable locomotor springs? J Exp Biol 205: 2211-2216, 2002.

13. Lynn R, Talbot JA, and Morgan DL. Differences in rat skeletal muscles after incline and decline running. J Appl Physiol 85: 98-104, 1998.

14. Maas H, Baan GC, and Huijing PA. Intermuscular interaction via myofascial force transmission: effects of tibialis anterior and extensor hallucis longus length on force transmission from rat extensor digitorum longus muscle. J Biomech 34: 927-940, 2001.

15. Marginson $\mathbf{V}$ and Eston R. The relationship between torque and joint angle during knee extension in boys and men. $J$ Sports Sci 19: 875-880, 2001.

16. Meijer K, Bosch P, Bobbert MF, Van Soest AJ, and Huijing PA. The isometric knee extension moment-angle relationship: experimental data and prediction based on cadaver data. $J$ Appl Biomech 14: 62-79, 1998.

17. Morgan DL. New insights into the behavior of muscle during active lengthening. Biophys $J$ 57: 209-221, 1990.

18. Neptune RR and Hull ML. Evaluation of performance criteria for simulation of submaximal steady-state cycling using a forward dynamic model. J Biomech Eng 120: 334-341, 1998.

19. Reiser RF, Peterson ML, and Broker JP. Influence of hip orientation on wingate power output and cycling technique. $J$ Strength Cond Res 16: 556-560, 2002.

20. Suzuki S, Watanabe S, and Homma S. EMG activity and kinematics of human cycling movements at different constant velocities. Brain Res 240: 245-258, 1982.

21. Van Ingen Schenau GJ, Boots PJ, De Groot G, Snackers RJ, and Van Woensel WW. The constrained control of force and position in multi-joint movements. Neuroscience 46: $197-$ 207, 1992.

22. Van Ingen Schenau GJ, Dorssers WM, Welter TG, Beelen A, De Groot G, and Jacobs R. The control of mono-articular muscles in multijoint leg extensions in man. $J$ Physiol 484: 247-254, 1995.

23. Wank V, Frick U, and Schmidtbleicher D. Kinematics and electromyography of lower limb muscles in overground and treadmill running. Int J Sports Med 19: 455-461, 1998.

24. Wickiewicz TL, Roy RR, Powell PL, and Edgerton VR. Muscle architecture of the human lower limb. Clin Orthop 179: 275-283, 1983. 